\title{
Voltammetric characterization of an iridium oxide-based system: the pseudocapacitive nature of the $\operatorname{Ir}_{0.3} \mathrm{Mn}_{0.7} \mathrm{O}_{2}$ electrode
}

\author{
A.A.F. Grupioni, E. Arashiro, T.A.F. Lassali * \\ Departamento de Física e Matemática, FFCLRP, Universidade de São Paulo, Av. Bandeirantes 3900, 14040-901 Ribeirão Preto, SP, Brazil
}

Received 16 September 2002

\begin{abstract}
Mixtures of $\mathrm{IrO}_{2}+\mathrm{MnO}_{2}(30: 70 \mathrm{~mol} \%)$ have been electrochemically studied by cyclic voltammetry (CV) in acid solution. The crystalline structure, morphology and the electrochemical properties of the electrodes have been studied as a function of the annealing temperature. X-ray diffraction analysis (XRD), show absence of $\mathrm{Mn}_{2} \mathrm{O}_{3}$ phase formation and suggest the possible of formation of a solid solution of $\mathrm{IrO}_{2}$ and $\mathrm{MnO}_{2}$ mainly between 400 and $450{ }^{\circ} \mathrm{C}$. The voltammetric behavior depends on the potential cycle number and annealing temperature employed in the preparation of the oxide layer. A good potential window in aqueous $\mathrm{H}_{2} \mathrm{SO}_{4}$ and high electroactive area are obtained due to the contribution of Ir redox transitions. Energy-dispersive X-ray (EDX) and scanning electron microscopy (SEM) analysis suggest an enrichment of the Ir content on the surface at the cost of the dissolution of the manganese present in the film when the electrode is submitted to the continuous potential scan. The electrodes have been found to perform well in electrochemical capacitor applications with a specific capacitance close to $550 \mathrm{~F} \mathrm{~g}^{-1}$. The large capacitance exhibited by this system arises from a combination of the double-layer capacitance and pseudocapacitance associated with surface redox-type reactions.
\end{abstract}

(C) 2002 Elsevier Science Ltd. All rights reserved.

Keywords: Supercapacitors; Iridium oxide; Manganese dioxide; Voltammetric behavior; Electrochemical properties

\section{Introduction}

Hydrous metal oxides have been found to possess significant energy storage capabilities, and represent the best materials for application in electrochemical capacitors [1,2]. The amorphous $\mathrm{RuO}_{2} \cdot x \mathrm{H}_{2} \mathrm{O}$ achieved the greatest importance among the oxide materials [3,4]. $\mathrm{RuO}_{2}$ systems prepared by the sol-gel process deliver the most capacitance and values up to $720 \mathrm{~F} \mathrm{~g}^{-1}$ have been reported [5]. Metal oxide capacitors provide the highest specific peak power $\left(>5 \mathrm{~kW} \mathrm{~kg}^{-1}\right)$, but the high cost of the active material $\left(\mathrm{RuO}_{2}\right)$ prevents some applications. One possible way to reduce the cost is to dilute the conductive oxide in a wider type of oxide

* Corresponding author. Tel.: +55-16-602-3822; fax: +55-16-6339949

E-mail addresses: agrupioni@universiabrasil.net (A.A.F. Grupioni), everaldo@quark.ffclrp.usp.br (E. Arashiro), tania@dfm.ffclrp.usp.br (T.A.F. Lassali). structure. Recent research efforts have attempted to minimize the noble oxide content by carrying out dispersion over high surface area substrates [6-10]. Among the various materials investigated for this purpose, attention has been recently paid to the manganese compounds [11]. $\mathrm{MnO}_{2}$ is an important material in electrochemical technology and has been widely used as an electrode in batteries. This oxide has good electronic conductivity and is capable of providing several redox reactions involving different oxidation states of Mn metal centers.

In this context, the ( $\mathrm{Ti}) \mathrm{IrO}_{2}+\mathrm{MnO}_{2}$ mixed electrode was prepared as a candidate for the supercapacitor device. A mixed oxide composition containing $30 \mathrm{~mol} \%$ $\mathrm{IrO}_{2}$ was chosen among the ones investigated to keep the high electronic conductivity of the film with a minimum amount of the expensive metal. $\mathrm{IrO}_{2}$ exhibits metallic conductivities at room temperatures and is the best conductor in the transition metal group. In the case of $\mathrm{RuO}_{2}+\mathrm{TiO}_{2}$ mixed oxides, the conductivity is 
dominated by $\mathrm{RuO}_{2}$ when it is present in amounts as low as $25-30 \mathrm{~mol} \%$ [12]. Similar behavior is expected for the $\mathrm{IrO}_{2}$-based systems. For the $\mathrm{IrO}_{2}+\mathrm{TiO}_{2}$ system, $\mathrm{Da}$ Silva et al. [13] observed that mixtures containing less than $20 \mathrm{~mol}^{\%} \mathrm{IrO}_{2}$ showed electrical properties dominated by $\mathrm{TiO}_{2}$.

The effect of the addition of $\mathrm{MnO}_{2}$ on the electrochemical performance of the $\mathrm{IrO}_{2}$-based electrode in 0.5 mol dm ${ }^{-3} \mathrm{H}_{2} \mathrm{SO}_{4}$ was analyzed as a function of calcination temperature $\left(T_{\mathrm{c}}\right)$ of the electrode. The potential range of the redox processes, the degree of their reversibility and the specific capacitance values were established by cyclic voltammetry (CV). In addition, the structure, morphology and real composition of the (Ti) $\mathrm{IrO}_{2}+\mathrm{MnO}_{2}(30: 70 \mathrm{~mol} \%)$ electrode were also systematically examined.

\section{Experimental}

\subsection{Electrode preparation}

Electrodes of (Ti) $\mathrm{IrO}_{2}+\mathrm{MnO}_{2}(30: 70 \mathrm{~mol} \%)$ nominal composition were prepared by thermal decomposition of a mixture of precursor $\sim 0.2 \mathrm{~mol} \mathrm{dm}^{-3}$ solutions of $\mathrm{IrCl}_{3} \cdot x \mathrm{HCl} \cdot y \mathrm{H}_{2} \mathrm{O}$ (Aldrich) and $\mathrm{MnCl}_{2} \cdot 2 \mathrm{H}_{2} \mathrm{O}$ (Merck) dissolved in $\mathrm{HCl}$ 1:1 (v/v). Both solutions had been lead

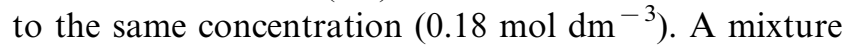
of appropriate volumes $(0.3 \mathrm{ml} \mathrm{Ir}$ and $0.7 \mathrm{ml} \mathrm{Mn}$ for 1 $\mathrm{ml}$ of total mixture) of the precursor solutions were spread by brushing both sides of the $10 \times 10 \times 0.15 \mathrm{~mm}^{3}$ Ti support, which had been pre-treated through sandblasting and etched in boiling $10 \%$ oxalic acid. After each application, the solvent was evaporated at about $90{ }^{\circ} \mathrm{C}$ and the dried layer was fired for $5 \mathrm{~min}$, under a 51 $\min ^{-1} \mathrm{O}_{2}$ stream, in a preheated oven. The deposited mass on the Ti support has been calculated based on the sum of the specific gravity of the $\operatorname{IrO}_{2}\left(11.665 \mathrm{~g} \mathrm{~cm}^{-3}\right)$ and $\mathrm{MnO}_{2}\left(5.026 \mathrm{~g} \mathrm{~cm}^{-3}\right)$ [14] considering the (30:70 $\mathrm{mol} \%$ ) ratio of and a nominal coating thickness value constant $(2 \mu \mathrm{m})$. The procedure was repeated until the desired catalyst loading was achieved $\left(1.41 \mathrm{mg} \mathrm{cm}^{-2}\right)$.

The oxide layer was prepared at different thermal decomposition temperatures $\left(400,450,500\right.$ and $\left.550{ }^{\circ} \mathrm{C}\right)$. (Ti) $\mathrm{IrO}{ }_{2}$ and $\mathrm{Ti} / \mathrm{MnO}_{2}$ electrodes were prepared at $450{ }^{\circ} \mathrm{C}$ employing the same procedure described above, which was adopted as a standard for the comparison of the electrochemical behavior of the binary system. The electrodes were then annealed for $1 \mathrm{~h}$ at the corresponding temperature. The mounting of the electrodes on a Teflon holder has been described elsewhere [15].

\subsection{Electrochemical measurement}

The surface features of the mixed oxides were characterized in situ by $\mathrm{CV}$ at $20 \mathrm{mV} \mathrm{s}^{-1}$ in the potential range of 0.4 to $1.4 \mathrm{~V}$ per RHE in $0.5 \mathrm{~mol}$ $\mathrm{dm}^{-3} \mathrm{H}_{2} \mathrm{SO}_{4}$ solutions. The electrodes were submitted to continuous cyclization of the potential for 100 cycles to evaluate their chemical stability and to reach a stationary surface condition. The double layer region was determined by progressive shifts of the positive and negative potential limit. The differential capacity $\left(C_{\mathrm{d}}\right)$ of the oxide/solution interface and the electrode roughness were obtained from $\mathrm{CV}$ measurements ranging from 5 to $150 \mathrm{mV} \mathrm{s}^{-1}$. The $C_{\mathrm{d}^{\text {-values }}}$ were obtained from the slope of the $j\left(\mathrm{~mA} \mathrm{~cm}{ }^{-2}\right)$ versus $v$ $\left(\mathrm{mV} \mathrm{s}^{-1}\right)$ graphics (were $j$ is the current density at the potential $E=1.38 \mathrm{~V}$ per RHE and $v$ is the voltage sweep rate, $\mathrm{d} V / \mathrm{d} t)$.

\subsection{Solution and equipment}

Electrochemical measurements were performed using a four-compartment cell with two counter electrodes (platinized platinum wires) facing the working electrode from opposite sides, and a Luggin capillary approaching the electrode from below in order to minimize uncompensated ohmic drop. Electrode potentials were measured and are reported against a hydrogen electrode in the same supporting electrolyte (RHE). The electrochemical experiments were carried out with an ECO CHEMIE Autolab Potentiostat/galvanostat (PGSTAT30) interfaced with a computer. All experiments were carried out in $0.5 \mathrm{~mol} \mathrm{dm}^{-3} \mathrm{H}_{2} \mathrm{SO}_{4}$ (Merck) solutions volumetrically prepared using Milli-Q quality distilled water. Solutions were dearated and stirred by bubbling nitrogen. All of the experiments were carried out at room temperature, approximately $25^{\circ} \mathrm{C}$.

The coating morphology and sample compositions were analyzed by scanning electron microscopy (SEM) and energy-dispersive X-ray (EDX) measurements using an electron microscope Zeiss Model DSM 960 coupled to a microanalyzer Link Analytical Model QX 2000. Quantitative analysis of the coating was performed by EDX. The atomic percentages of the elements were obtained through corrections of matrix interference, atomic number, absorbance and fluorescence (ZAF correction). Metallic cobalt (99.998\% pure) was used for equipment calibration. Iridium and cobalt reference standards (Micro-Analysis Consultants, Cambridgeshire) were used for internal calibration. The experimental errors, based on the ZAF correction algorithm, were always below $1 \%$ (wt.\%).

The microstructural investigation was carried out by X-ray diffraction analysis (XRD) of the powdered samples. These analyses were performed on a SIEMENS D5005 diffractometer using $\mathrm{CuK} \alpha$ radiation $(30 \mathrm{kV}, 30$ $\mathrm{mA})$. 


\section{Results and discussion}

\subsection{Morphology and composition characterization}

The real composition of the oxide layer of the (Ti) $\mathrm{IrO}_{2}+\mathrm{MnO}_{2}$ electrodes was determined by EDX analyses. The atomic percentages of $\mathrm{Ir}, \mathrm{Mn}$ and $\mathrm{Cl}$ present in different regions of the film were analyzed and listed in Table 1 as a function of the annealing temperatures for fresh sample prepared and after electrochemical experiments. For fresh samples, the EDX analyses showed that the real composition of the oxide layer is quite close to the nominal value. A small amount of $\mathrm{Cl}$ ( $\sim 2-3 \%$ in atom) was also detected in the oxide layer by EDX analysis, which is probably associated to incomplete decomposition of the precursors. Increase in the annealing temperature reduced the $\mathrm{Cl}$ content due to an increase in the efficiency of the decomposition of the precursors.

Typical SEM micrographs of the (Ti) $\mathrm{IrO}_{2}+\mathrm{MnO}_{2}$ electrodes are shown in Fig. 1 as a function of the annealing temperature, $T_{\mathrm{c}}$. The preparation of the mixed layer between 400 and $550{ }^{\circ} \mathrm{C}$ did not produce appreciable morphological differences in fresh samples prepared (Fig. 1A-C). All coatings were heterogeneous, containing randomly distributed agglomerates, cracks and pits. At low temperatures $\left(400-450{ }^{\circ} \mathrm{C}\right)$ the layers were rough with a non-crystalline appearance, indicating that thermal decomposition was incomplete. At higher temperatures, on the other hand, the layers appeared to be more compact. This result suggests a higher surface area for electrodes prepared at the lower temperature range $\left(400-450{ }^{\circ} \mathrm{C}\right)$.

It was also possible to observe the presence of countless bright particles randomly distributed on the surface in the case of the electrodes prepared at 500 and $550{ }^{\circ} \mathrm{C}$. This behavior is characteristic of a non-homogeneous surface composition and suggests segregation of different components. The punctual EDX analyses of brighter parts showed higher Ir content while the compact regions were highly enriched in manganese
(Table 1). The higher the $T_{\mathrm{c}}$ value, the higher the amount of bright particles and the greater the Ir content observed in the EDX analyses (Table 1). The nonuniform distribution of Ir is in agreement with previous findings [10], as was also observed by other authors for the (Ti) $\mathrm{IrO}_{2}+\mathrm{SnO}_{2}, \quad(\mathrm{Ti}) \mathrm{RuO}_{2}+\mathrm{IrO}_{2}+\mathrm{SnO}_{2}$ and (Ti) $\mathrm{IrO}_{2}+\mathrm{SnO}_{2}+\mathrm{TiO}_{2}$ systems [16-18]. SEM and EDX analyses suggest that an increase in $T_{\mathrm{c}}$ favors phase splitting between the different components, thus promoting $\mathrm{IrO}_{2}$ segregation on the surface of the electrode.

\subsection{Microstructural analysis}

Fig. 2 shows the X-ray diffraction patterns of $\mathrm{Ir}_{0.3} \mathrm{Mn}_{0.7} \mathrm{O}_{2}$ powder as a function of thermal decomposition. Three main broad peaks of low intensity are observed for all the samples, independent of $T_{\mathrm{c}}$. These X-ray diffraction patterns are characteristic of a highly disordered material, suggesting that the thermal treatment produced a mixed oxide of low crystalline degree. This result is in line with the possible incomplete decomposition of the precursors in the annealing temperature range used. This behavior is probably related to the fact that the annealing temperature necessary to transform all chloride into dioxide is higher than $550{ }^{\circ} \mathrm{C}$ in the experimental conditions employed. It is well known that the thermal decomposition temperature of a precursor is very dependent on its nature, concentration and the solvent employed because the kinetics and the decomposition mechanism are dependent on preparation parameters. Values of $390-600{ }^{\circ} \mathrm{C}$ have been reported in the literature for the preparation of $\mathrm{IrO}_{2}$, depending on the experimental conditions employed $[19,20]$. For oxide mixtures, the film composition also influences the thermal decomposition value of the precursors. Kristof et al. [20] observed that the conversion temperature of iridium chloride into iridium oxide decreases from 600 to $400{ }^{\circ} \mathrm{C}$ when the Ir content changes from 100 to $10 \mathrm{~mol} \%$ in the $\mathrm{IrO}_{2}+\mathrm{TiO}_{2}$ mixed oxide.

Table 1

Atomic percentages obtained from EDX analyze for (Ti) $\mathrm{IrO}_{2}+\mathrm{MnO}_{2}(30: 70 \mathrm{~mol} \%)$ mol electrodes as a function of annealing temperature

\begin{tabular}{|c|c|c|c|c|c|c|c|c|c|c|}
\hline \multirow[t]{3}{*}{$T\left({ }^{\circ} \mathrm{C}\right)$} & \multicolumn{5}{|c|}{ Global regions } & \multicolumn{5}{|c|}{ Clear regions } \\
\hline & \multicolumn{2}{|c|}{$\operatorname{Ir}(30)^{*}$} & \multicolumn{2}{|c|}{$\operatorname{Mn}(70)^{*}$} & \multirow{2}{*}{$\begin{array}{l}\mathrm{Cl} \\
\text { (1) }\end{array}$} & \multicolumn{2}{|l|}{$\mathrm{Ir}$} & \multicolumn{2}{|l|}{$\mathrm{Mn}$} & \multirow{2}{*}{$\frac{\mathrm{Cl}}{\text { (2) }}$} \\
\hline & (1) & (2) & (1) & (2) & & (1) & (2) & (1) & (2) & \\
\hline 400 & 28 & 36 & 69 & 64 & 3 & - & 44 & - & 56 & - \\
\hline 450 & 33 & 89 & 64 & 11 & 3 & - & 81 & - & 17 & - \\
\hline 500 & 26 & 85 & 72 & 15 & 2 & 36 & 84 & 52 & 16 & 2 \\
\hline 550 & 27 & 83 & 72 & 17 & 1 & 42 & 77 & 66 & 22 & 2 \\
\hline
\end{tabular}

(1) Fresh sample prepared.

(2) After electrochemical experiments.

* nominal values. 


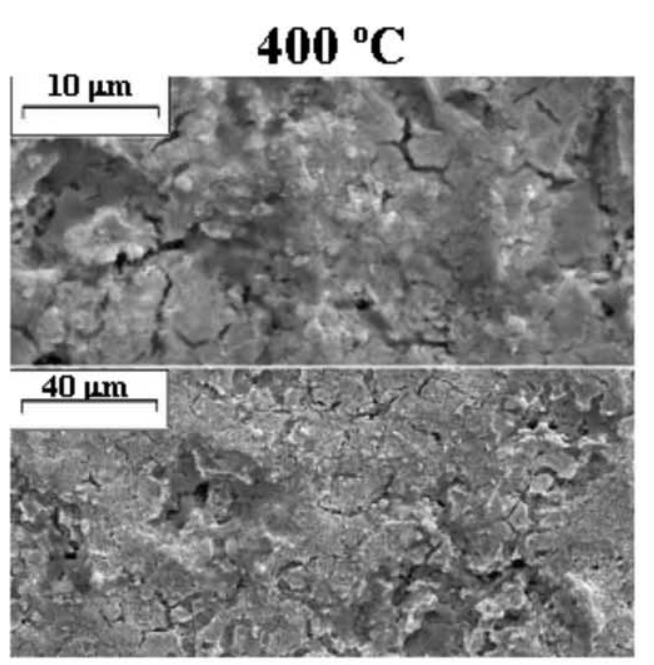

(A)

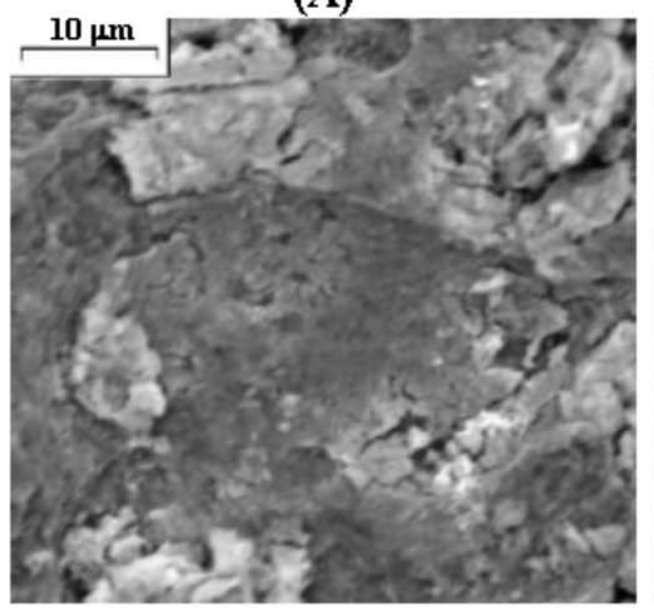

(D)

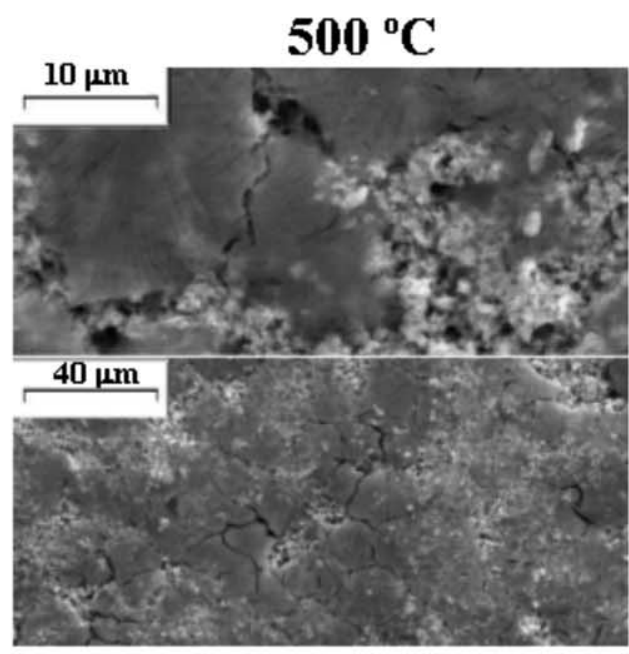

(B)

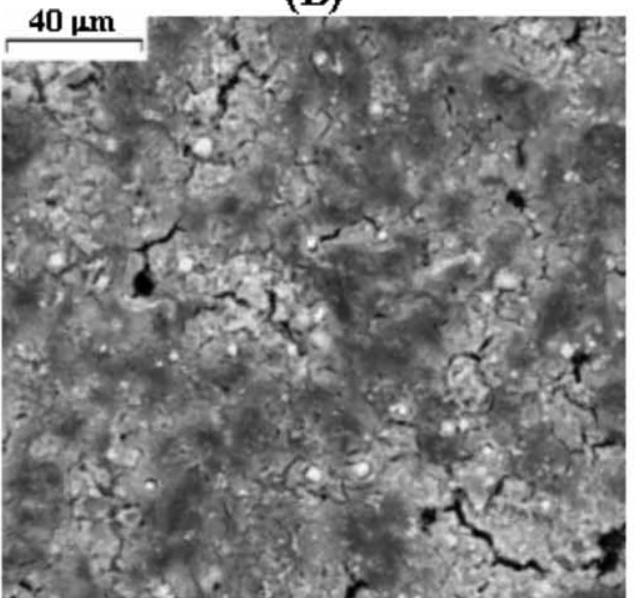

(E)

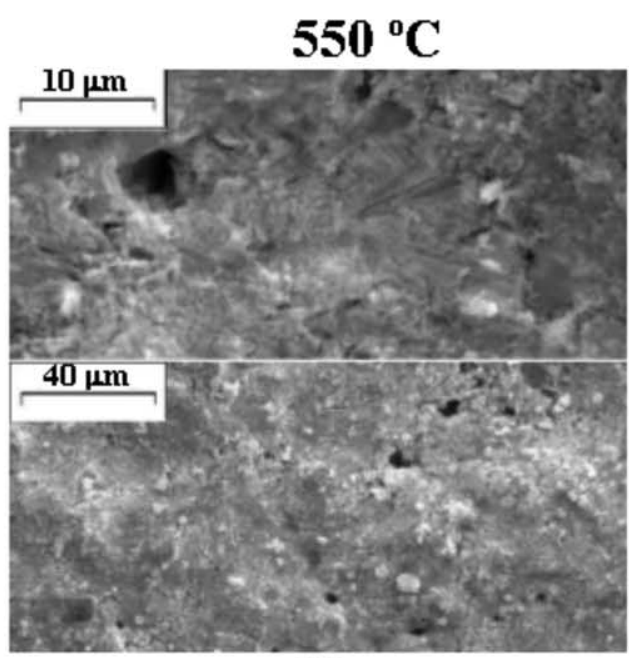

(C)

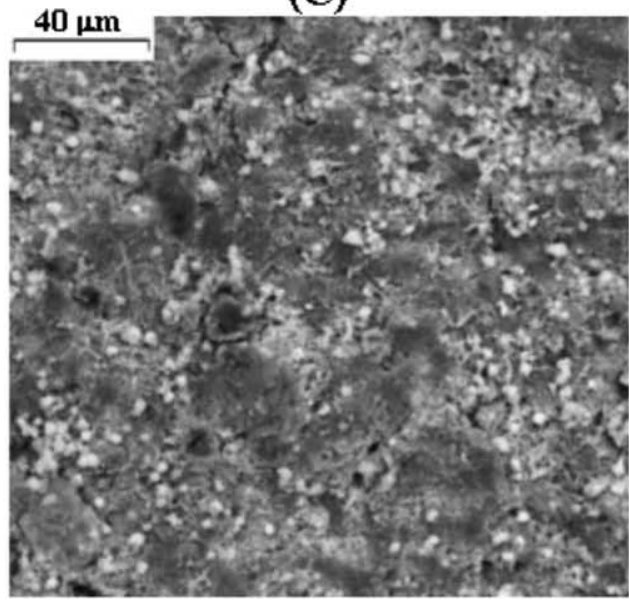

(F)

Fig. 1. SEM micrographs of (Ti) $\operatorname{Ir}_{0.3} \mathrm{Mn}_{0.7} \mathrm{O}_{2}$ electrodes as a function of annealing temperature. (A), (B) and (C): Freshly prepared electrodes. (D), (E) and (F): After electrochemical experiments. 


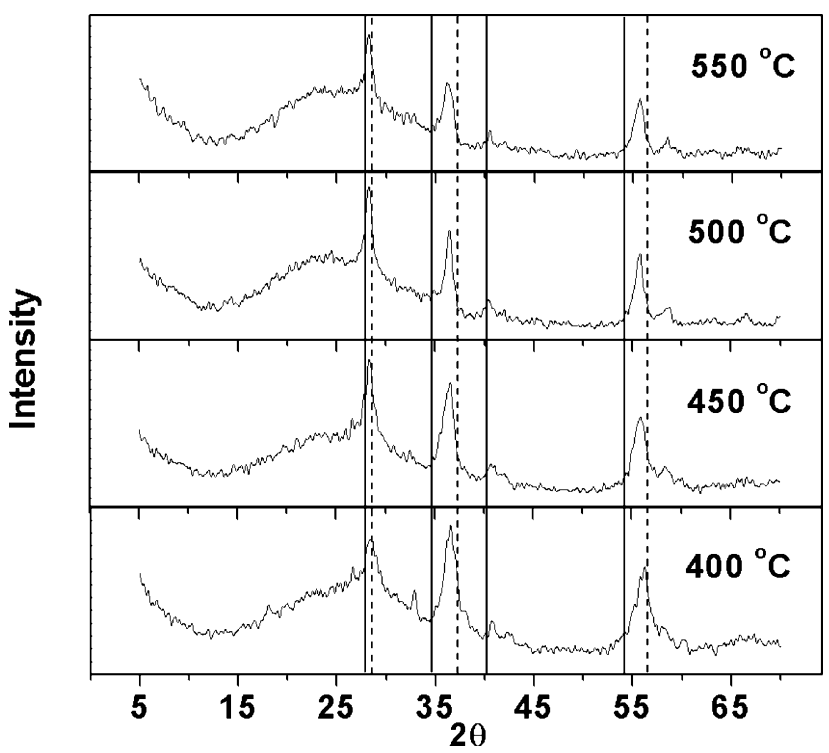

Fig. 2. X-ray diffraction patterns of $(\mathrm{Ti}) \mathrm{Ir}_{0.3} \mathrm{Mn}_{0.7} \mathrm{O}_{2}$ electrodes as a function of annealing temperature. Position of the peaks expected for the $\mathrm{IrO}_{2}(----)$ and $\mathrm{MnO}_{2}(-)$ tetragonal structure.

$\mathrm{X}$-ray diffractograms of the mixed oxides showed regular shifts in the position of the peaks expected for the $\mathrm{IrO}_{2}$ and $\mathrm{MnO}_{2}$ tetragonal structure, indicating a reciprocal solubility of the two components. This result is in line with the Hume-Rothery conditions because both oxides have a tetragonal structure, and similar ionic radius and valence. Therefore, XRD analyses suggest that the mixed oxide system formed a solid solution of $\mathrm{IrO}_{2}$ and $\mathrm{MnO}_{2}$ with the rutile-type structure, for the studied composition.

For comparison, the XRD spectrum of the pure component powders prepared at 400 and $550{ }^{\circ} \mathrm{C}$ are shown in Fig. 3. For the iridium oxide prepared at

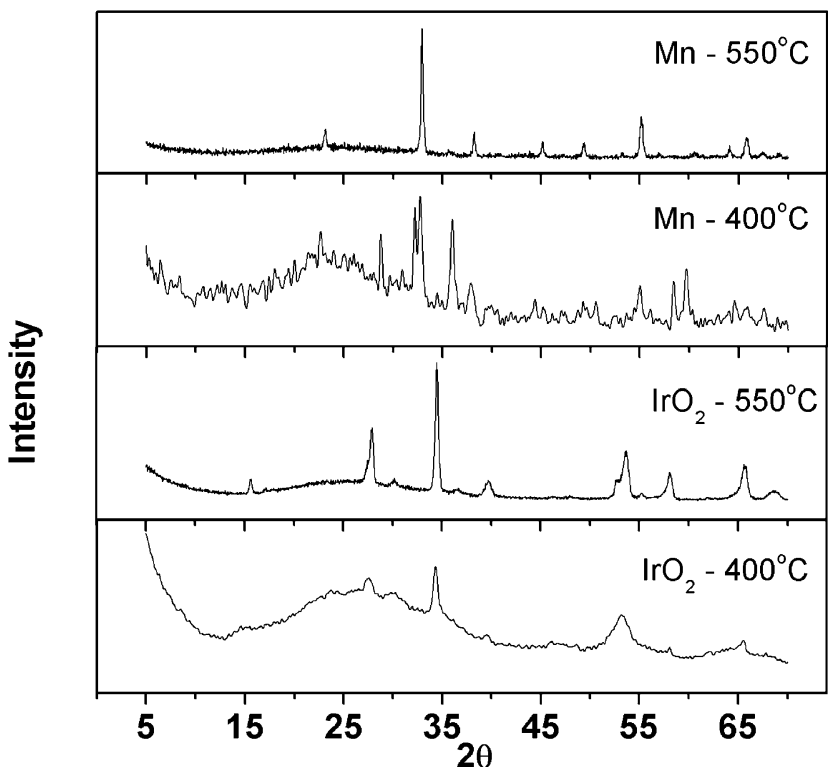

Fig. 3. X-ray diffraction patterns of $\mathrm{MnO}_{2}$ and $\mathrm{IrO}_{2}$ powder samples heat-treated at 400 and $550{ }^{\circ} \mathrm{C}$.
$400{ }^{\circ} \mathrm{C}$, the XRD spectrum shows broad and low intense peaks that can be related to the most intense diffraction peaks of the rutile phase (Fig. 3). The X-ray pattern of the sample prepared at $550{ }^{\circ} \mathrm{C}$ shows peaks with a better definition, indicating that thermal treatment leads to an increase in the crystallization degree of the material due to a more complete decomposition of the precursor.

An increase in the crystallization degree with the value of $T_{\mathrm{c}}$ was not observed for the (Ti) $\mathrm{IrO}_{2}+\mathrm{MnO}_{2}$ system, suggesting that the mixed oxide makes the thermal decomposition of the components difficult (Fig. 2). Increase in the $T_{\mathrm{c}}$ promoted an improvement in the definition of the peak observed at $2 \theta=28^{\circ}$ and a displacement in the position of the other peaks to values closer to those expected for the $\mathrm{IrO}_{2}$-rutile structure. This behavior is in agreement with the SEM and EDX analyses, suggesting a reduction in the solubility of the two components and an increase in the importance of $\mathrm{IrO}_{2}$ for the physical-chemical properties of the system.

The representative XRD pattern (Fig. 3), of the manganese oxide deposited at $400{ }^{\circ} \mathrm{C}$ showed reflections related to different types of oxides $\left(\mathrm{Mn}_{2} \mathrm{O}_{3}\right.$ and $\mathrm{MnO}_{2}$ polymorphs). For higher temperatures, only the $\mathrm{Mn}_{2} \mathrm{O}_{3}$ phase was observed (Fig. 3). This result is in line with the decomposition temperature value of $420{ }^{\circ} \mathrm{C}$ reported for $\mathrm{MnO}_{2}-\mathrm{Mn}_{2} \mathrm{O}_{3}$ conversion [21]. For comparison, the absence of the $\mathrm{Mn}_{2} \mathrm{O}_{3}$ phase in the X-ray diffractogram of the binary oxide system reinforces the possible formation of a solid solution of $\mathrm{IrO}_{2}$ and $\mathrm{MnO}_{2}$ in the temperature range of the preparation studied. This behavior suggests promising properties for the technological application of the $\mathrm{IrO}_{2}+\mathrm{MnO}_{2}$ mixture, since $\alpha$ $\mathrm{Mn}_{2} \mathrm{O}_{3}$ has a higher electric resistance than $\beta-\mathrm{MnO}_{2}$ [21].

\subsection{Voltammetric behavior}

Fig. 4 shows typical cyclic voltammograms for (Ti) $\mathrm{IrO}_{2}+\mathrm{MnO}_{2}$ electrodes recorded between 0.4 and $1.4 \mathrm{~V}$ per RHE as a function of the potential cycle number $(n)$ and annealing temperature, $T_{\mathrm{c}}$. All the electrodes exhibited a voltammogram typical of the DSA-type oxide electrodes with a pseudocapacitive behavior. The electrochemical response was typical of a capacitor exhibiting roughly rectangular mirror images and rapid reversals of directions of response currents for $n>2$.

The voltammetric behavior depends on the potential cycle number $(n)$ and $T_{\mathrm{c}}$ employed in the preparation of the oxide layer. For the electrode prepared at $400{ }^{\circ} \mathrm{C}$ and $n=2$, two broad bands are present between 0.5-0.6 and $0.9-1.0 \mathrm{~V}$ per RHE during the positive and negative going scans. Similar voltammetric behavior was observed for an $\mathrm{IrO}_{2}$ film prepared by reactive sputtering [22] and for a (Ti) $\mathrm{IrO}_{2}+\mathrm{SnO}_{2}$ system [23] suggesting that both redox transitions are related with the surface electrochemistry of iridium in acid solution. 
(A)

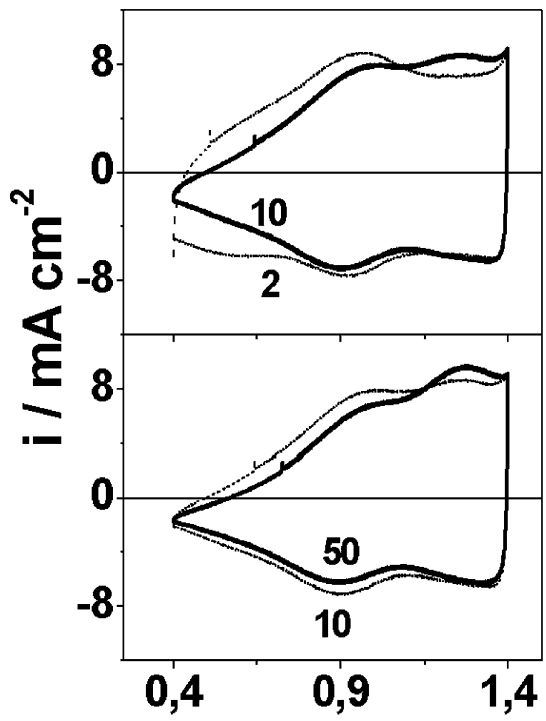

(B)

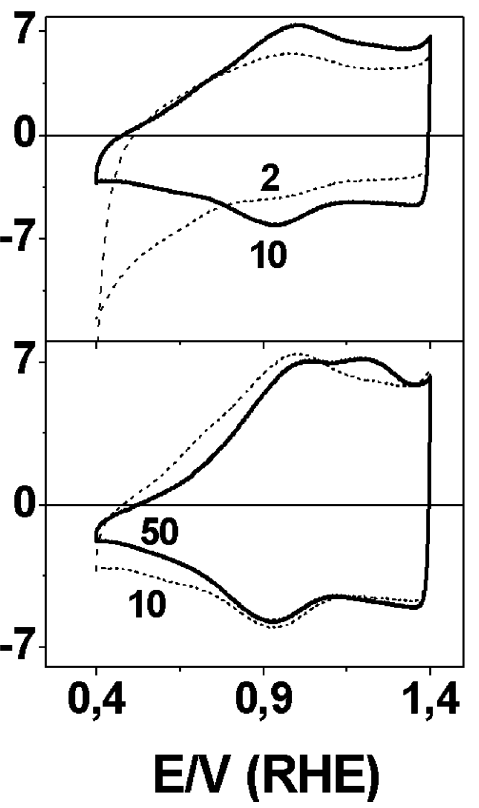

(C)

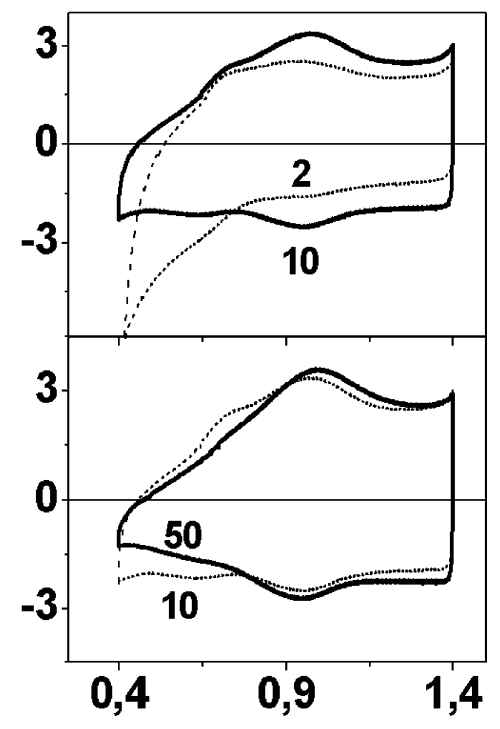

Fig. 4. Cyclic voltammograms of $(\mathrm{Ti}) \mathrm{Ir}_{0.3} \mathrm{Mn}_{0.7} \mathrm{O}_{2}$ electrodes between 0.4 and $1.4 \mathrm{~V}$ per RHE as a function of annealing temperature in 0.5 mol $\mathrm{dm}^{-3} \mathrm{H}_{2} \mathrm{SO}_{4}$ at $20 \mathrm{mV} \mathrm{s}^{-1}$. (A) 400; (B) 450 and (C) $550{ }^{\circ} \mathrm{C}$. Cycle number of potential is shown inset in the figure.

The pair of bands between 0.9 and $1.0 \mathrm{~V}$ per RHE is attributed to the $\operatorname{Ir}(\mathrm{III}) / \mathrm{Ir}(\mathrm{IV})$ solid state redox transitions. The mechanism of this reaction is based on the double ion-electronic injection (or ejection) of electron and counter ion $\left(\mathrm{H}^{+}\right.$or $\left.\mathrm{OH}^{-}\right)$, compensating for the change of the charge on the oxide film. This model requires that a hydrated oxide be formed on the surface. Consequently, the ionic transport is influenced by hydration degree and the porous structure of the oxide layer.

The hint of a pair of peak located at $\sim 0.55 \mathrm{~V}$ per RHE can be related to a prepeak preceding the Ir(III)/ Ir(IV) redox transition frequently observed in electrolitically grown hydrated oxide films on iridium [24-29]. This prepeak is absent in the $\mathrm{Ti} / \mathrm{IrO}_{2}$ electrodes prepared at $450{ }^{\circ} \mathrm{C}$ employing the same procedure described to mixed oxide (see Fig. 5a). This behavior suggests that the chemical state of the surface is different in oxide layer obtained from $\mathrm{IrO}_{2}+\mathrm{MnO}_{2}$ mixed that observed to $\mathrm{Ti} / \mathrm{IrO}_{2}$ electrode. In agreement with the SEM and EDX analyses for fresh samples, this may indicate that thermal treatment in the $\mathrm{Ti} / \mathrm{IrO}_{2}+\mathrm{MnO}_{2}$ electrodes leads to a more incomplete decomposition of the precursors thus acquiring a partly hydrous nature which makes their voltammogram similar to that one observed in electrolitically grown hydrated oxide films on iridium.

The increase in $T_{\mathrm{c}}$ promoted some significant changes in the voltammetric feature of the $I-E$ profiles. Smaller voltammetric currents are obtained by increasing the preparation* temperature; this behavior can be explained as a consequence of a decrease in the effective surface area due to the phenomena of crystallization and sintering at higher temperatures [30]. Besides the two redox bands described for $T_{\mathrm{c}}=400{ }^{\circ} \mathrm{C}$, it is possible to observe a current tail as the negative-going potential increases at initial cycles $(n=2)$ in the case of the higher temperature. The presence of this cathodic current suggests the occurrence of an irreversible reduction process involving active sites of the oxide layer. After some few cycles it is possible to observe that a region of capacitive nature substitutes the cathodic current tail (see Fig. 4 to $n=10$ ).

Similar behavior is observed in the voltammogram of the $\mathrm{Ti} / \mathrm{MnO}_{2}$ electrode, prepared in the same experimental condition, indicating that cathodic current is probably related to the partial reduction of the $\mathrm{Mn}$ surface sites (Fig. 5B) when the fresh electrode is submitted to cathodic scan. It is possible to observe a continuous decrease in the voltammetric charge with $n$ to the (Ti) $\mathrm{MnO}_{2}$ electrodes probably related to gradual dissolution of the oxide layer. According to Pang et al. [11], this reduction process involves the incorporation of protons in the crystalline structure of $\mathrm{MnO}_{2}$ dehydrated sites with dilatation of the crystalline net and the eventual formation of a $\mathrm{MnOOH}$ amorphous phase. The reduction mechanism has been suggested to be a combination of electrochemical and chemical dissolution steps when acid solutions are used as electrolyte support $[31,32]$.

The effect of potential scan on the voltammetric behavior also shows dependence on the thermal treatment of the oxide layer. For the electrode prepared at 

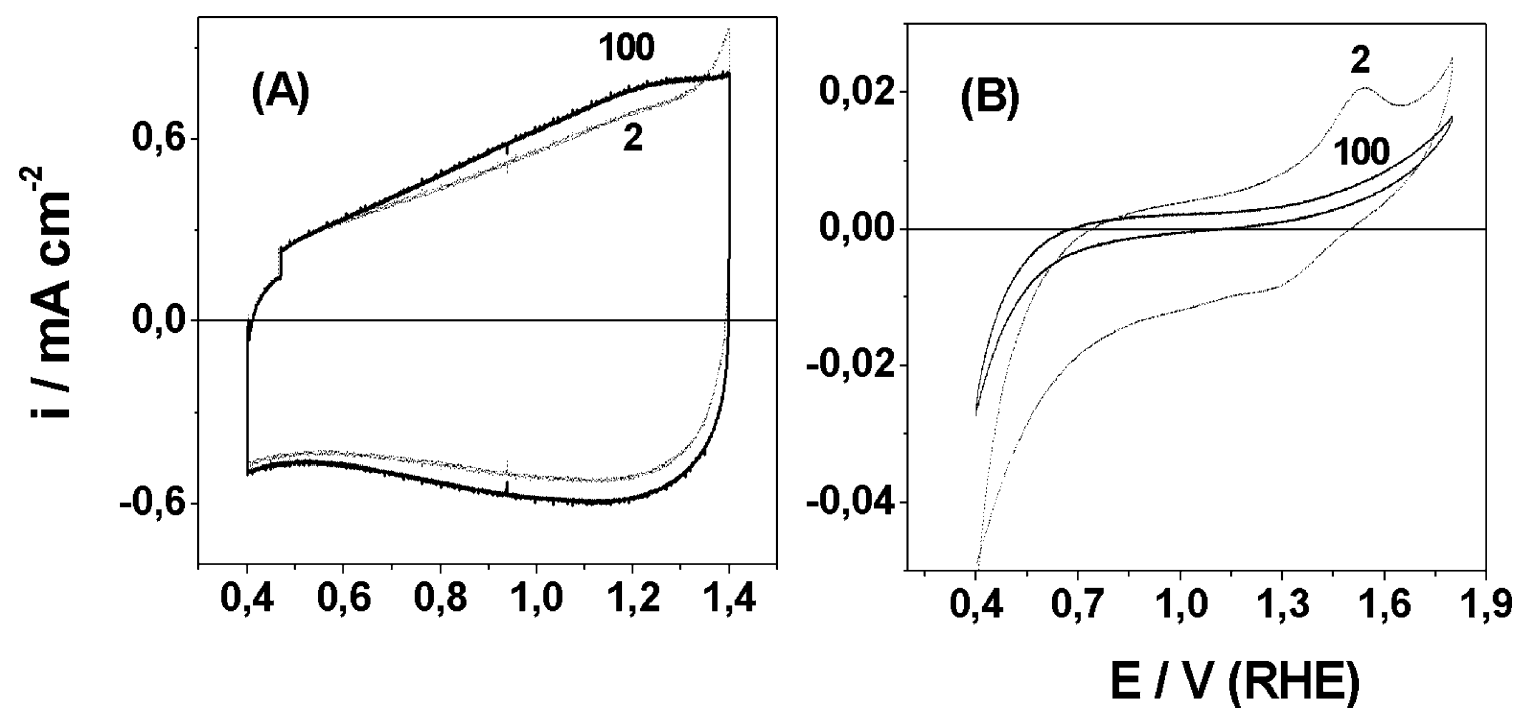

Fig. 5. Cyclic voltammograms of (Ti) $\mathrm{IrO}_{2}(\mathrm{~A})$ and $(\mathrm{Ti}) \mathrm{MnO}_{2}$ (B) electrodes between 0.4 and $1.4 \mathrm{~V}$ per RHE in $0.5 \mathrm{~mol} \mathrm{dm}^{-3} \mathrm{H}_{2} \mathrm{SO}_{4}$ at $20 \mathrm{mV}^{-1}$. Cycle number of potential is shown inset in the figure.

$400{ }^{\circ} \mathrm{C}$, the potential scan up to ten cycles promotes disappearance of a pair of humps localized at $\sim 0.55 \mathrm{~V}$ per RHE. After ten cycles, it is possible to observe the presence of a peak at $1.2 \mathrm{~V}$ per RHE. The change in the voltammetric behavior with the number of cycles suggests that potential scan promoted some alterations in the surface composition of the electrode. The higher the cycles number, the more intense the band related to the new process is and more similar the voltammetric profile to that one observed for electrolitically grown films on iridium Probably the oxide layer acquire a partly hydrous nature due to an increase in the number of the hydrophilic sites responsible for proton and electron transfer in the redox process in the film.

These changes in the voltammmetric behavior are very similar to that one observed by M. Vukovic [33] to hydrous oxide films grown on iridium followed by heat treatment and submitted to square-wave pulses from 0.25 to $+1.25 \mathrm{~V}$ (SCE) at $2 \mathrm{~Hz}$ for $5 \mathrm{~min}$. The voltammetric profile of hydrous oxide film is restored after square-wave activation of the anhydrous film and the new anodic peak close to $1.1 \mathrm{~V}$ (RHE) is also observed. This similarity of behavior suggests that the process observed in $1.2 \mathrm{~V}$ per $\mathrm{RHE}$ to $\mathrm{Ti} / \mathrm{IrO}_{2}+\mathrm{MnO}_{2}$ electrodes is related to iridium active sites.

For electrodes prepared at $T_{\mathrm{c}}>400{ }^{\circ} \mathrm{C}$ and $n>2$, it is possible to observe a continuous increase in the voltammetric charge due to gradual wetting of the internal porosity. This allows a progressive bulk hydroxylation of the oxides. The disappearance of the pair of humps localized at $\sim 0.55 \mathrm{~V}$ per RHE is only observed after 20 cycles. The solid-state redox transition observed in $1.2 \mathrm{~V}$ per RHE is only visible after continuous potential scan. The higher the $T_{\mathrm{c}}$-value, the more potential cycles are necessary to observe this surface redox process and the more dislocated to cathodic direction is the peak potential value $\left(E_{\mathrm{p}}\right)$ related to this process. For the electrode prepared at $550{ }^{\circ} \mathrm{C}$, it is only possible to observe one solid-state redox transition, independent of the value of $n$.

The different behavior observed for the (Ti) $\mathrm{IrO}_{2}+$ $\mathrm{MnO}_{2}$ system as a function of $n$ and $T_{\mathrm{c}}$ can be better understood by analyzing of the oxide layer composition and the morphology of the (Ti) $\mathrm{IrO}_{2}+\mathrm{MnO}_{2}$ electrode after repetitive potential cycling. Typical SEM micrograph of the electrodes after intensive use is shown in Fig. $1 \mathrm{D}-\mathrm{F}$ as a function of $T_{\mathrm{c}}$. Significant changes were not observed in the morphology of the electrode prepared at $400{ }^{\circ} \mathrm{C}$ after the intensive use. However, SEM micrographs reveal a substantial change in the oxide layer morphology for electrodes prepared between 450 and $550{ }^{\circ} \mathrm{C}$ (Fig. $1 \mathrm{E}$ and F). Besides the increase in the number cracks and the porosity of the oxide layer, it is also possible to observe the presence of countless agglomerates (light areas) on the surface of the samples. This result suggests that after repetitive potential scan the oxide layer becomes much more heterogeneous in composition, probably due to preferential $\mathrm{Mn}$ dissolution. The number of agglomerates increases with increasing calcination temperature of the oxide layer, confirming a reduction in the solubility of the two components.

While the EDX analysis of the electrode prepared at $400{ }^{\circ} \mathrm{C}$ and submitted to electrochemical study shows similar values for Ir and Mn content (Table 1) to those in the fresh sample, electrodes annealed at $T_{\mathrm{c}}>400$ show higher Ir content and an appreciable reduction in the amount of manganese. This result confirms that the cathodic tail observed in the voltammetric behavior is related to $\mathrm{Mn}$ preferential dissolution when the oxide layer is prepared at higher annealing temperatures. The 
higher the temperature of sample preparation, the lower is amount of manganese remaining in the oxide layer.

The punctual analysis of specific regions of the coating confirms that light areas detected in the SEM micrographs (Fig. 1D-F) are rich in $\mathrm{IrO}_{2}$. This result suggests an enrichment of the Ir content on the surface at the cost of the dissolution of the manganese present in the film when the electrode is submitted to the continuous potential scan.

\subsection{Effects of the positive and negative potential limit}

Voltammetric curves were recorded by progressively shifting the positive and negative potentials with the purpose of investigating the maximum potential range available in $0.5 \mathrm{~mol} \mathrm{dm}{ }^{-3} \mathrm{H}_{2} \mathrm{SO}_{4}$. Fig. 6 shows the voltammetric curves obtained at different potential limits to (Ti) $\mathrm{IrO}_{2}+\mathrm{MnO}_{2}$, (Ti) $\mathrm{IrO}_{2}$ and (Ti) $\mathrm{MnO}_{2}$ electrodes prepared at $450{ }^{\circ} \mathrm{C}$. A potential range of 1.45 $\mathrm{V}$ was obtained without any apparent decomposition of water for Ir-based electrodes. Electrocatalytic activity for the $\mathrm{O}_{2}$ evolution reaction (OER) was observed for all the Ir-based electrodes above $1.45 \mathrm{~V}$ per RHE and after $1.8 \mathrm{~V}$ (RHE) to the $\mathrm{Ti} / \mathrm{MnO}_{2}$. This result suggests that Ir active sites domains the electrocatalytic activity of the system.

Two different patterns are observed to (Ti) $\mathrm{IrO}_{2}+$ $\mathrm{MnO}_{2}$ and $\mathrm{Ti} / \mathrm{IrO}_{2}$ electrodes with negative potential limit. For (Ti) $\mathrm{IrO}_{2}+\mathrm{MnO}_{2}$ electrodes, the cathodic potential limit does not change the shape of the voltammetric curve independent of $T_{\mathrm{c}}$ value. This behavior is similar to that one observed to $\mathrm{IrO}_{2}$ electrodes prepared at $T \leq 360{ }^{\circ} \mathrm{C}$ in $1 \mathrm{M} \mathrm{NaOH}$ [34]. For Chen and Trasatti [34], this behavior indicates that the current flowing below $E=0.4 \mathrm{~V}$ per RHE does not involve proton injection into the active layer. The voltammetric profile is very similar to that observed in anodic iridium oxide films grown on iridium surface $[33,34]$. The $\mathrm{Ti} / \mathrm{IrO}_{2}$ voltammetric behavior is the same observed to electrode prepared in ref. [34] for $T>$ $360{ }^{\circ} \mathrm{C}$ suggesting that electrode show anhydrous oxide film characteristics.
The progressive shift of the cathodic potential limit for (Ti) $\mathrm{MnO}_{2}$ electrode promoted an intensification of the anodic band observed close to $1.6 \mathrm{~V}$ per RHE. It is possible to notice the same effect with solid-state redox transition observed at $\sim 1.2 \mathrm{~V}$ per RHE to (Ti) $\mathrm{IrO}_{2}+$ $\mathrm{MnO}_{2}$ electrode independently of $T_{\mathrm{c}}$.

The (Ti) $\mathrm{IrO}_{2}+\mathrm{MnO}_{2}$ electrodes were submitted to continuous cyclization of the potential between 0.0 and $1.4 \mathrm{~V}$ per ERH to $20 \mathrm{mV} \mathrm{s}^{-1}$. The purpose was to investigate the stability of the oxide layers in this new condition. While the voltammetric current for the electrode prepared at $400{ }^{\circ} \mathrm{C}$ decreases continually with $n$-values, the other electrodes do not show any change in the voltammetric behavior. This result suggests that while the process of the Mn dissolution occurs in a continuous and slow way for the electrode prepared at $400{ }^{\circ} \mathrm{C}$, for the other samples this process is very fast and occurs soon after the first cycles.

\subsection{Effect of the scan rate between 0.4 and $1.4 \mathrm{VIERH}$}

The influence of the scan rate on the performance of the electrodes annealed at different $T_{\mathrm{c}}$ values is shown in Fig. 7. The anodic-cathodic charge ratio, $q_{\mathrm{a}} / q_{\mathrm{c}}$, remains close to one, independent of the scan rate value $(v)$. This indicates that the oxidation and reduction processes at the electrode interface are highly reversible. All samples show a cyclic voltammogram with a linear relationship between the peaks current $\left(j_{\mathrm{p}}\right)$ and the scan rate $(v)$ for the redox processes observed at 0.9 and $1.2 \mathrm{~V}$. This clearly indicates that the reactants must be confined at the interface. Deviation from linearity was observed for the $\operatorname{Ir}(\mathrm{III}) / \mathrm{Ir}(\mathrm{IV})$ redox process only at scan rates faster than $50 \mathrm{mV} \mathrm{s}^{-1}$. This behavior is generally found in porous structures where the faster scan promotes exclusion of the surface regions that are difficult to access and is due to ohmic-drop effects.

However, there are some differences in the voltammetric behavior of these curves when the $v$-value is increased. While the value of the anodic peak current $\left(i_{\mathrm{ap}}\right)$ related to the Ir redox process is more intense at lower potential scan rates, the $i_{\mathrm{ap}}$-value of the band close

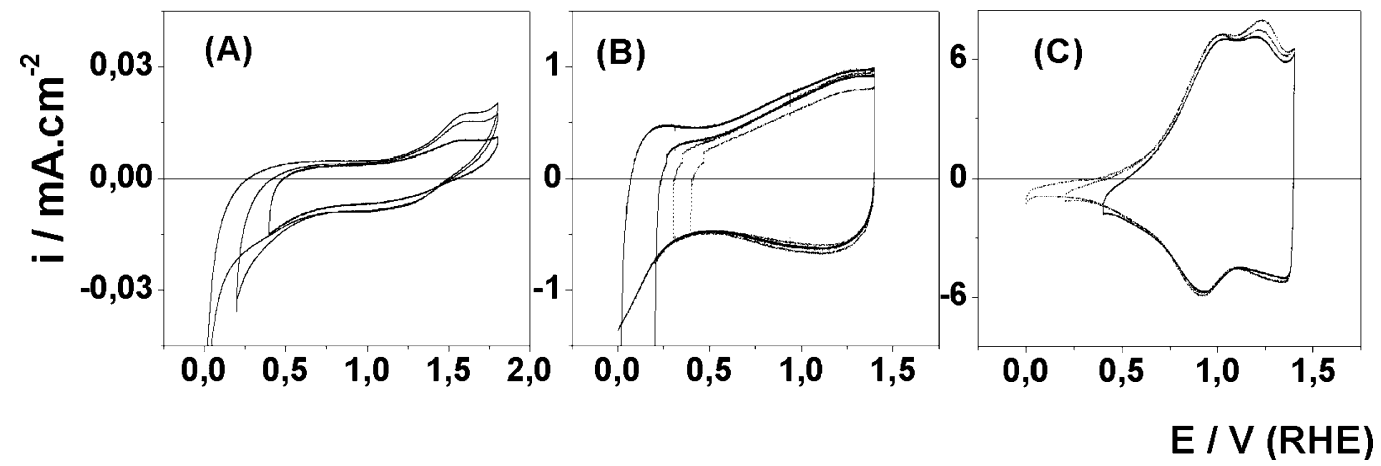

Fig. 6. Voltammetric curves obtained at different potential limits to the (Ti) $\mathrm{MnO}_{2}(\mathrm{~A})$, ( $\left.\mathrm{Ti}\right) \mathrm{IrO}_{2}(\mathrm{~B})$ and $\mathrm{Ti} / \mathrm{Ir}_{0.3} \mathrm{Mn}_{0.7} \mathrm{O}_{2}(\mathrm{C})$ electrodes in $0.5 \mathrm{~mol}$ $\mathrm{dm}^{-3} \mathrm{H}_{2} \mathrm{SO}_{4}$ at $20 \mathrm{mV} \mathrm{s}^{-1}$. 
(A)

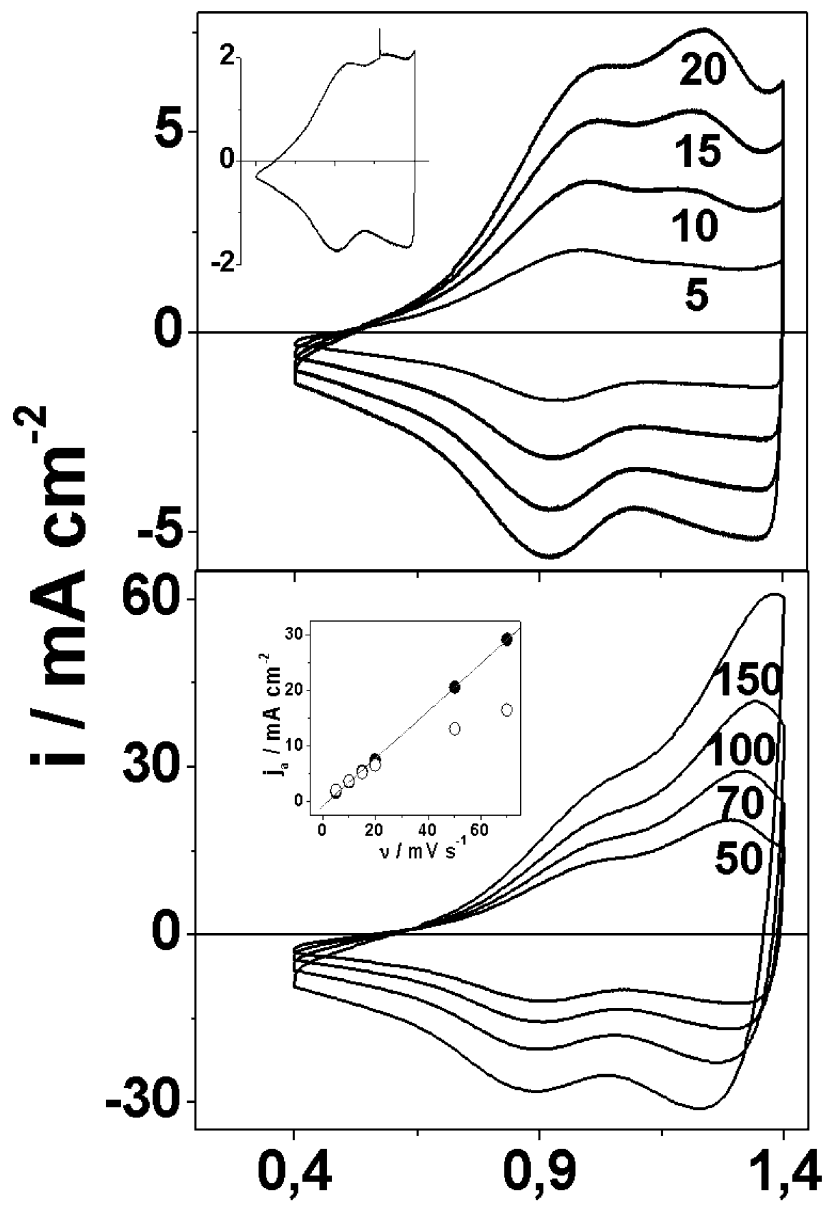

(B)

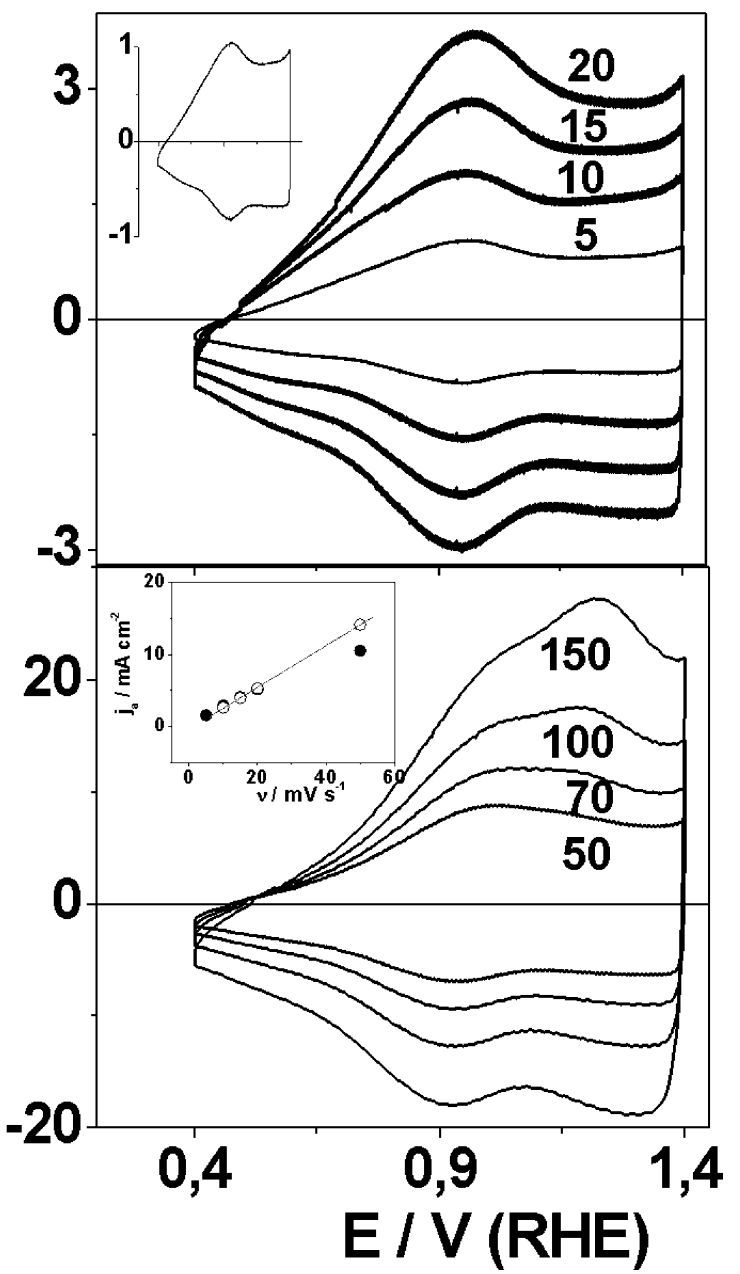

Fig. 7. Voltammetric behavior as a function of the scan rate, $v$, between 0.4 and $1.4 \mathrm{~V}$ per ERH in $0.5 \mathrm{~mol} \mathrm{dm}^{-3} \mathrm{H}_{2} \mathrm{SO}_{4}$ at $20 \mathrm{mV} \mathrm{s}^{-1}$ (inset shows the voltammetric curve obtained to for $v=5 \mathrm{mV} \mathrm{s}^{-1}$ ). (A) 450 and (B) $550{ }^{\circ} \mathrm{C}$.

to $1.2 \mathrm{~V}$ per RHE increases more significantly with $v$ values and becomes more intense than that observed for the $\operatorname{Ir}(\mathrm{III}) /(\mathrm{IV})$ redox transition at a faster scan rate. In other words, the charge associated with the first anodic peak decreases while that associated with the second anodic peak increases with increasing scan rate.

On the other hand, while both band are observed in the cyclic voltammogram of the electrodes prepared at $400-450{ }^{\circ} \mathrm{C}$ independent of $v$-values, for the sample annealed above $450{ }^{\circ} \mathrm{C}$ it is only possible to detect the presence of a wave close to $1.2 \mathrm{~V}$ per RHE above $5 \mathrm{mV}$ $s^{-1}$ (see inset of Fig. 6). These data suggest that the two anodic processes (close to 0.98 and $1.2 \mathrm{~V}$ per RHE) are sensitive to a different degree to the kinetics (potential scan rate) and the oxide microstructure (annealing temperature), respectively.

Similar behavior was observed in Ir oxide films grown in $0.5 \mathrm{~mol} \mathrm{dm}^{-3} \mathrm{H}_{2} \mathrm{SO}_{4}$ as a function of $v[25,26]$. Pickup and Birss [25] related to this behavior with the occurrence of a $\operatorname{Ir}(\mathrm{III} / \mathrm{IV})$ and $\operatorname{Ir}(\mathrm{IV} / \mathrm{V} / \mathrm{VI})$ waves overlap in the $0.9-1.3 \mathrm{~V}$ potential range. For Burke and Whelan
[25] the Ir redox process observed close to $0.9 \mathrm{~V}$ occurs through a hopping mechanism involving electron exchange between $\operatorname{Ir}($ III) and Ir(IV) adjacent sites and that generation of $\operatorname{Ir}(\mathrm{VI})$ sites at positive potentials enhances the electron hopping rate significantly. In base in this mechanism, Pickup and Birss [26] argued that as the $v$ is increased, the rate of electron hopping between the $\operatorname{Ir}(\mathrm{III})$ and $\operatorname{Ir}(\mathrm{IV})$ sites becomes insufficient to maintain equilibrium within the oxide. However, when the potential is high enough to generate $\operatorname{Ir}(\mathrm{V})$ and/or Ir(VI) sites, the charge transport rate increases and the film reaches equilibrium. When the $v$ value is increased, more $\operatorname{Ir}(\mathrm{V})$ and/or $\operatorname{Ir}$ (VI) sites are necessaries to promote a new equilibrium situation shifting the $E_{\mathrm{p}}$ to higher values. This mechanism is in agreements with the behavior described to (Ti) $\mathrm{IrO}_{2}+\mathrm{MnO}_{2}$ system and confirmed the similarity observed in the anodically grown Ir oxide electrodes. However, a systematic study involving changes in the composition of the oxide layer and XPS analyses are being carried out in our laboratory to check this proposal. 
Independently of $T_{\mathrm{c}}$-value employed in the film preparation, the oxide layer is constitued of a mixture of crystalline and hydrated amorphous oxides, the latter due to incomplete precursor composition. The presence of a hydrated amorphous oxide phase in the oxide layer can explain the participation of Ir-sites located in the most difficult-to-access region to the solid-state redox transition.

We believe that two types of interfaces can be involved in the charging process of the oxide layer prepared by thermal decomposition: (a) the oxide/ solution interface of the freely accessible external surface; (b) the oxide/solution interface of the adjacent, the most difficult-to-access surface (e.g. inside pores). The double layer charging process involves the occurrence of $\operatorname{Ir}(\mathrm{III}) / \operatorname{Ir}(\mathrm{IV})$ solid state transitions in the $\mathrm{a}$ and $\mathrm{b}$ type interface. This solid state transition occurs with the participation of proton exchange between the oxide$\mathrm{OH}$ surface groups and the solution, according to the equation (1):

$\mathrm{M}(\mathrm{OH})_{x} \mathrm{O}_{y}+\delta \mathrm{H}^{+}+\delta \mathrm{e} \leftrightarrow \mathrm{M}(\mathrm{OH})_{x+\delta} \mathrm{O}_{y-\delta}$

Spectroscopy studies confirmed the presence of $-\mathrm{OH}$ groups at the surface and at more intern oxide surface [35] without evidencing, however, the presence of water molecules in the most intern areas of the oxide layer. The mechanism by which internal regions can be active in reactions involving water molecules is that the $-\mathrm{OH}$ surface groups behave as acids or weak bases, thus acting as a proton source.

The more amorphous the oxide formed by the thermal decomposition method is, higher is the importance of $b$ type interface in the charging process of the film. In fact, the incomplete precursor decomposition results in an oxide phase having oxy-hydroxide species with ability to act as active sites. XRD analyses suggest that the presence of a hydrated amorphous oxide phase is favored by $\mathrm{MnO}_{2}$ introduction in the oxide layer. After Mn dissolution a higher among of Ir hydrated oxide is exposed to solution. Only after this dissolution process, the cyclic voltammogram assumes a similar behavior observed to hydrous oxide films grown on iridium and the process close to $1.2 \mathrm{~V}$ is detected. The presence of this band seems to be related to the hydration degree of the oxide layer. This relation explains the change in the voltammetric behavior of the system with the $v$ when the film preparation temperature is increased.

\subsection{Charge capacitance between 0.4 and 1.4 VIERH}

Values for the differential capacitance $\left(C_{\mathrm{d}}\right)$ were estimated from $\mathrm{CV}$ experiments by measuring the slope of the voltammetric current density versus scan rate plot at $E=1.38 \mathrm{~V}$ per RHE. The current values were measured after 100 cycles of potential scan between
0.4 and $1.4 \mathrm{~V}$ per REH to guarantee that the surface reached a stationary-state situation after the dissolution process observed in the first cycles. The advantage of measuring the voltammetric current at this potential value is the fact that it includes the contribution of both redox transitions (observed at 0.9 and $1.2 \mathrm{~V}$ per RHE) for the specific capacitance of the system. The roughness factor, $R_{\mathrm{F}}$, was calculated assuming a $\mathrm{C}$ of $80 \mu \mathrm{F} \mathrm{cm}{ }^{-2}$ for a smooth oxide surface [36]. The specific capacitance, $\mathrm{C}_{\mathrm{s}}$, was obtained by dividing the $C_{\mathrm{d}}$ value by the Ir mass content $\left(m_{\text {Ir }}\right)$ of the oxide layer $\left(\mathrm{g} \mathrm{cm}^{-2}\right)$. Although the specific capacitance of mixed oxides should be reported on the basis of the total weight of the oxide, in this paper the $C_{\mathrm{s}}$-value is measured as a function of the content of the noble oxide $\left(\mathrm{IrO}_{2}\right)$. This is done with the objective of evaluating the effect of the reduction of the amount of the precious component to $30 \mathrm{~mol} \%$ on the total charge capacity.

$q_{\mathrm{a}}, C_{\mathrm{d}}, C_{\mathrm{s}}$ and $R_{\mathrm{F}}$ values are summarized in Table 2 as a function of the annealing temperature. For comparison, $q_{\mathrm{a}}, C_{\mathrm{d}}, C_{\mathrm{s}}$ and $R_{\mathrm{F}}$ values obtained for the $\mathrm{Ti} / \mathrm{IrO}_{2}$ electrode annealed at $450{ }^{\circ} \mathrm{C}$ are also shown in Table 2 .

The anodic surface charge, $q_{\mathrm{a}}$, represents the number of protons exchanged between the oxide surface and the solution according to the equation (1). This can be considered a measure of the surface area [37], which is in turn related to the morphology of the oxide layer [38]. All the electrodes exhibit higher $q_{\mathrm{a}}$ values than that observed for $\mathrm{Ti} / \mathrm{IrO}_{2}$ prepared at $450{ }^{\circ} \mathrm{C}$. This suggests an increase in the electroactive surface area promoted by the mixture of different oxides. This increase can be understood if one considers that the introduction of the second component promoted dispersion of the Ir active surface sites, increased the content of oxy-hydroxide species with ability to act as active sites and that other oxidation states had started to contribute with the charging process of the electrode.

The high $R_{\mathrm{F}}$-values observed in the case of all the analyzed electrodes are intimately related to the large double-layer capacitance $\left(C_{\mathrm{dl}}\right)$ due to high surface area of the samples (which is made up of microcrystallites separated by highly defective regions due to rugosity, microporosity, cracks, etc.). However, the $R_{\mathrm{F}}$-values showed in the Table 2 are enormous, truly nanoporous films of comparable thickness do not show so high values [39]. These high values also arise of the pseudocapacitive behavior of the material, which originates from the faradaic reactions at the interface between the electroactive materials and electrolytes.

The electrodes prepared at $400-450{ }^{\circ} \mathrm{C}$ show $R_{\mathrm{F}^{-}}$ values three times as high as those at observed for $T_{\mathrm{c}}>$ $450{ }^{\circ} \mathrm{C}$. It has been demonstrated that parameters such as the degree of hydration of the oxide and its crystallinity play essential roles in the amount of charge exchanged between the electrode and the electrolytic solution [5]. Experiments on hydrous Ru oxides [5,40] 
Table 2

Values of anodic charge, $q_{\mathrm{a}}^{*}$ (to $\left.n=2\right) q_{\mathrm{a}}$ (to $n=100$ ), differential capacitance, $C_{\mathrm{d}}$, specific capacitance, $C_{\mathrm{s}}$ and roughness factor, $R_{\mathrm{F}}$, estimated from $\mathrm{CV}, 20 \mathrm{mV} \mathrm{s}^{-1}$

\begin{tabular}{llllll}
\hline$T\left({ }^{\circ} \mathrm{C}\right)$ & $q_{\mathrm{a}}^{*}\left(\mathrm{mC} \mathrm{cm}^{-2}\right)$ & $q_{\mathrm{a}}\left(\mathrm{mC} \mathrm{cm}^{-2}\right)$ & $C_{\mathrm{d}}\left(\mathrm{F} \mathrm{cm}^{-2}\right)$ & $C_{\mathrm{s}}\left(\mathrm{F} \mathrm{g} \mathrm{g}^{-1}\right)$ & 557 \\
\hline 400 & 299 & 234 & 0.449 & 410 & 5613 \\
450 & 182 & 207 & 0.342 & 251 & 4275 \\
500 & 160 & 178 & 0.221 & 213 & 2763 \\
550 & 86 & 108 & 0.139 & 21 & 1788 \\
$\mathrm{Ti} / \mathrm{IrO}{ }_{2}\left(450^{\circ} \mathrm{C}\right)$ & - & 36 & 0.0529 & 661 \\
\hline
\end{tabular}

$C^{*}=80 \mu \mathrm{F} \mathrm{cm}^{-2}$.

have shown that it has a substantially larger charge storage capacity that anhydrous $\mathrm{RuO}_{2}$. According to Zheng et al. [5], amorphous Ru oxides allow the whole bulk of $\mathrm{RuO}_{2}$ to be used for charging storage due to the fast proton transport rates. Removal of structural water from the oxide with the $T_{\mathrm{c}}$ increases the results in lowering the proton transport through the oxide. This result suggests that if one wants to obtain electrodes of high surface area and high charge capacitance, the precursors should be annealed at $400-450{ }^{\circ} \mathrm{C}$ temperature ranges.

$q_{\mathrm{a}}, C_{\mathrm{d}}, C_{\mathrm{s}}$ and $R_{\mathrm{F}}$ values decrease with the annealing temperature, suggesting a decrease in the real surface area. This result is in agreement with SEM analyses that show a more compact oxide layer at higher temperatures. This decrease also suggests a decrease in the number of active sites available to participate in reaction (1).

The anodic charge, $\left(q_{\mathrm{a}}^{*}\right)$ of the $\mathrm{CV}$ between 0.4 and 1.4 $\mathrm{V}$ per RHE at $n=2$ and $20 \mathrm{mV} \mathrm{s}^{-1}$, before the $\mathrm{Mn}$ dissolution process, is also included in Table 2. This was done with the aim of evaluating the effect of dissolution process on the electroactive area of the electrodes by comparison of this parameter with the value obtained before the potential scan. This parameter gives an idea of the morphological conditions of the electrode surface soon after preparation, excluding the effects of $\mathrm{Mn}$ dissolution. The $q_{\mathrm{a}}^{*}$ value decreases with the annealing temperature in a way similar to that for $q_{\mathrm{a}}$. A comparison between the $q_{\mathrm{a}}^{*}$ and $q_{\mathrm{a}}$ values show that the Mn dissolution process did not promote significant reduction in the value of the voltammetric charge. On the other hand, after potential scan for 100 cycles between 0.4 and $1.4 \mathrm{~V}$ per REH, an increase in the $q_{\mathrm{a}}$ value was obtained for the electrodes prepared at higher annealing temperature. The $q_{\mathrm{a}}$ decrease observed for the electrode prepared at $400{ }^{\circ} \mathrm{C}$ should be related to loss through erosion of the most external part of the oxide layer.

Maximum $C_{\mathrm{s}}$ values were obtained for electrodes prepared at lower temperatures. However, the instability of the oxide layer with the potential cyclization shows that temperatures lower than $450{ }^{\circ} \mathrm{C}$ are not adequate for the preparation of the electrodes in acid solution.
The value obtained for the electrode prepared at $450{ }^{\circ} \mathrm{C}$ is at least 19 times higher than that observed for the Ti/ $\mathrm{IrO}_{2}$ system in similar experimental conditions $(21 \mathrm{~F}$ $\left.\mathrm{g}^{-1}\right)$. Only a minimum amount of noble oxide $(<1 \mathrm{mg})$ was required to produce a significant increase in the charge capacity, maintaining the high conductivity of the oxide layer.

The $C_{\mathrm{s}}$-values observed for the electrode prepared at $450{ }^{\circ} \mathrm{C}$ is not as high as that obtained for hydrated $\mathrm{RuO}_{2}\left(720 \mathrm{~F} \mathrm{~g}^{-1}\right.$ was measured for the powder formed at $150{ }^{\circ} \mathrm{C}$ ) [5]. The difference in charge capacity among these systems is mainly related to the fact that in the $\mathrm{Ru}$ based system, where the composite is completely amorphous, the entire bulk of $\mathrm{RuO}_{x}$ takes part in the faradaic reaction. However, the $C_{\mathrm{s}}$ value obtained for $\mathrm{IrO}_{2}+\mathrm{MnO}_{2}$ prepared at $450{ }^{\circ} \mathrm{C}$ is higher than those obtained for anhydrous $\mathrm{RuO}_{2}$-based electrodes prepared at $400{ }^{\circ} \mathrm{C}\left(380 \mathrm{~F} \mathrm{~g}^{-1}\right.$ at a scan rate of $100 \mathrm{mV}$ $\mathrm{s}^{-1}$ [41] and $19.2 \mathrm{~F} \mathrm{~g}^{-1}$ for $\mathrm{RuO}_{2} \cdot x \mathrm{H}_{2} \mathrm{O}$ prepared by Zheng et al. [5]). In similar preparation conditions, where due to a high $T_{\mathrm{c}}$ value most of the external part of the oxide layer just participates in reaction (1), the Irbased system shows a higher charge capacity than the one observed for $\mathrm{RuO}_{2}$.

The large capacitance exhibited by this system arises from a combination of the double-layer capacitance (due to high surface area) and pseudocapacitance associated with surface redox-type reactions. $\mathrm{MnO}_{2}$ addition to the oxide layer promoted a considerable increase in the specific capacitance of the electrode due to an increase in the surface area promoted by a higher microporosity degree and also promoted an enrichment of the Ir content on the surface of the electrode at cost of the dissolution of the manganese present in the film.

\section{Conclusion}

(Ti) $\mathrm{IrO}_{2}+\mathrm{MnO}_{2}$ electrodes prepared by thermal decomposition $\left(400-550^{\circ} \mathrm{C}\right)$ show high electroactive area, independent of the annealing temperature. All the electrodes exhibit a pseudocapacitive behavior and surface properties controlled by the Ir active sites. DRX analysis shows absence of the formation of a $\mathrm{Mn}_{2} \mathrm{O}_{3}$ 
phase. This suggests the possible formation of a solid solution of $\mathrm{IrO}_{2}$ and $\mathrm{MnO}_{2}$ with a rutile-type structure, mainly at $400-450{ }^{\circ} \mathrm{C}$. The chemical state of the surface is different in the oxide layer obtained from $\mathrm{IrO}_{2}+$ $\mathrm{MnO}_{2}$ mixed from that observed to $\mathrm{Ti} / \mathrm{IrO}_{2}$ electrode indicating that thermal treatment in the $\mathrm{Ti} / \mathrm{IrO}_{2}+\mathrm{MnO}_{2}$ electrodes leads to a more incomplete decomposition of the precursors thus acquiring a partly hydrous nature. A partial dissolution of the Mn surface sites is observed when the fresh electrode is submitted to cathodic scan, independent of the $T_{\mathrm{c}}$ value. This behavior is related to the thermodynamic instability of Mn species in the acid solution. An enrichment of the Ir content on the surface of the electrode at cost of the dissolution of the manganese present in the film was observed when the electrode was submitted to continuous potential scan. After Mn dissolution, it was possible to observe the presence of a peak at $1.2 \mathrm{~V}$ per RHE, attributed to higher Ir solid-state redox transitions.

A good potential window $(1.4 \mathrm{~V})$ and high electroactive area are obtained in aqueous $\mathrm{H}_{2} \mathrm{SO}_{4}$ due to the contribution of Ir redox transitions. $\mathrm{MnO}_{2}$ addition to the oxide layer promotes considerable increase in the specific capacitance of the electrode. This is due to an increase in the surface area promoted by high microporosity degree, as well as due to changes in the nature of the oxide film. After $\mathrm{Mn}$ dissolution process, Ir actives sites domain the surface properties and the voltammetric behavior assumes similar aspect of electrolitically grown hydrated oxide films on iridium. The system shows large capacitance due to a combination of the double-layer capacitance and pseudocapacitance associated with surface redox-type reactions. Increase in the $T_{\mathrm{c}}$-values promotes little decrease in the values of $C_{\mathrm{s}}$.

\section{Acknowledgements}

T.A.F.L. acknowledges financial support received from FAPESP (Brazil). A.A.F.G. also acknowledges FAPESP for a fellowship. The authors are grateful to Professor O. Savadogo for his valuable contribution to the final version of this paper.

\section{References}

[1] J.S. Sarangapani, B.V. Tilak, C.-P. Chen, J. Electrochem. Soc. 143 (1996) 3791

[2] B.E. Conway, J. Electrochem. Soc. 138 (1995) 1539.

[3] C.-C. Hu, Y.-H. Huang, Electrochim. Acta 46 (2001) 3431.

[4] J.H. Lim, D.J. Choi, H.-K. Kim, W.I. Cho, Y. Soo, J. Electrochem. Soc. 148 (2001) A275.
[5] J.P. Zheng, P.J. Cygan, T.R. Jow, J. Electrochem. Soc. 142 (1995) 2699.

[6] P. Soudan, J. Gaudet, D. Guay, D. Bélanger, R. Schulz, Chem. Mater. 14 (2002) 1210.

[7] M. Ramani, B.S. Haran, R.E. White, B.N. Popov, J. Electrochem. Soc. 148 (2001) A374.

[8] Y.U. Jeong, A. Manthiram, J. Electrochem. Soc. 148 (2001) A189.

[9] F. Cao, J. Prakash, J. Power Sources 92 (2001) 40.

[10] A. Grupioni, T.A.F. Lassali, J. Electrochem. Soc. 148 (2001) A1015.

[11] S.-C. Pang, M.A. Anderson, T.W. Chapman, J. Electrochem. Soc. 148 (2001) A189.

[12] P.H. Duvigneaud, A. Coussment, J. Solid State Chem. 52 (1984) 22.

[13] L.A. Da Silva, V.A. Alves, M.A.P. da Silva, S. Trasatti, J.F.C. Boodts, Can. J. Chem. 75 (1997) 1483.

[14] R.C. Weast (Ed.), Handbook of Chemistry and Physics, 55th ed, CRC Press, Baton Roca, FL, 1974, p. 1975.

[15] R. Garavaglia, C.M. Mari, S. Trasatti, Surf. Technol. 23 (1984) 41.

[16] C.P. De Pauli, S. Trasatti, J. Electroanal. Chem. 396 (1995) 161.

[17] R. Hutchings, K. Müller, R. Kötz, S. Stucki, J. Mater. Sci. 19 (1984) 3987.

[18] T.A.F. Lassali, L.O.S. Bulhões, L.M.C. Abeid, J.F.C. Boodts, J. Electrochem. Soc. 144 (1997) 3349.

[19] G.-W. Yang, K. Rajeshwar, J. Electrochem. Soc. 134 (1830) 1987.

[20] J. Kristóf, J. Liszi, P. Szabó, A. Barbieri, A. De Battisti, J. Appl. Electrochem. 23 (1993) 615.

[21] A. Kozawa, Proceedings of Symposium on $\mathrm{MnO}_{2}$ Electrode, vol. 85-4, The Electrochemical Society Proceedings Series, Pennington, NJ, 1985, pp. 384.

[22] T. Pauporté, D. Aberdam, J.-L. Hazemann, R. Faure, R. Durant, J. Electroanal. Chem. 465 (1999) 88.

[23] T.A.F. Lassali, J.F.C. Boodts, L.O.S. Bulhões, J. Non Cryst. Sol. $273(2000) 129$

[24] B.E. Conway, J. Mozota, Electrochim. Acta 28 (1983) 9.

[25] L.D. Burke, D.P. Whelan, J. Electroanal. Chem. 162 (1984) 121.

[26] P.G. Pickup, V.I. Birss, J. Electroanal. Chem. 240 (1988) 185.

[27] S. Gottesfeld, A. Redondo, I. Rubenstein, S.W. Feldberg, J. Electroanal. Chem. 265 (1989) 15.

[28] H. Elzanowska, V.I. Birss, J. Appl. Electrochem. 23 (1993) 646.

[29] H. Elzanowska, J. Segal, V.I. Birss, Electrochim. Acta 44 (1999) 4515.

[30] S. Trasatti, G. Lodi, in: S. Trasatti (Ed.), Electrodes of Conductive Metallic Oxides, Part B, Elsevier, Amsterdam, 1981.

[31] S. Nijjer, J. Thonstad, G.M. Haarberg, Electrochim. Acta 46 (2001) 3503.

[32] M. Pourbaix, Atlas of Electrochemical Equilibria in Aqueous Solutions, Pergamon Press, Oxford, 1966.

[33] M. Vukovic, J. Appl. Electrochem. 20 (1990) 969.

[34] H. Chen, S. Trasatti, J. Appl. Electrochem. 23 (1993) 559.

[35] R. Kötz, H. Neff, S. Stucki, J. Electrochem. Soc. 131 (1984) 72.

[36] S. Levine, A.L. Smith, Discuss. Faraday Soc. 52 (1971) 290.

[37] S. Trasatti, Electrochim. Acta 36 (1991) 225.

[38] S. Ardizzone, A. Carugati, S. Trasatti, J. Electrochem. Soc. 129 (1982) 1689.

[39] P. Soudan, J. Gaudet, D. Guay, D. Bélanger, R. Schulz, Chem. Mater. 14 (2002) 1210.

[40] T.R. Jow, J.P. Zheng, J. Electrochem. Soc. 145 (1998) 49

[41] I.D. Raistrick, in: J. McHardy, F. Luduig (Eds.), The Electrochemistry of Semiconductors and Electronics-Processes and Devices, Noyes, Park Ridge, NJ, 1992, p. 297. 